\title{
LAPAROSCOPIC SLEEVE GASTRECTOMY WITH LOOP BIPARTITION MORE PHYSIOLOGICAL TECHNIQUE: ONE YEAR EXPERIENCE
}

\author{
Mohamed K. Mansey, Ahmed E. Morad, Karim S. Abd El Samee, and \\ Hossam G. Radwan*
}

\begin{abstract}
Department of General Surgery Faculty of Medicine, Ain Shams University, Cairo, Egypt.

* Specialist of general surgery at mokattum health insurance hospital. Cairo, Egypt
\end{abstract}

Corresponding author

Hossam Gamal El-Din Radwan

Mobile: (+2) 01001158699

E.mail:

drradwan.h@gmail.com

Received: 21/1/2021

Accepted: 18/2/2021

Online ISSN: 2735-3540

\begin{abstract}
:
Background: Overweight and obesity were estimated to cause 3.4 million deaths, $3.9 \%$ of years of life lost, and 3.8\% of disabilityadjusted life-years (DALYs) worldwide. Bariatric surgery is the most effective modality for long-term weight loss and for resolving the associated comorbidities. However, controversies exist regarding the ideal weight loss metabolic procedure. This allowed continuous search for new techniques.
\end{abstract}

Aim of the work: to evaluate short-term outcomes and associated complications of laparoscopic sleeve gastrectomy with loop bipartition.

Patients and Methods: The present study was conducted on fifteen patients who met the National Institute of Health criteria for bariatric surgery. These patients were enrolled in a prospective study at Ain-Shams University Hospitals from December 2015 to May 2017) and they underwent laparoscopic sleeve gastrectomy with loop bipartition. Preoperative work up included full history, full clinical examination, abdominal ultrasonography, biochemical labs. Procedure was performed by laparoscopic approach.

Results: excess weight loss percentage at 6 months, 12 months respectively was $67 \%, 92 \%$. This results were very comparable to mahdy et al. and santoro et al. Sleeve gastrectomy with loop bipartition comorbidities related outcomes were complete remission of $66 \%$ in T2DM, $71 \%$ in HTN, $100 \%$ others comorbidities and another studies for bipartition reached more than 90\% in T2DM, 80\% in HTN, 85\% others comorbidities. In our study we recorded that Sleeve gastrectomy with loop bipartition has strong impact on resolution of comorbidities in comparison with BPD, DS, RYGB.

Conclusion: Sleeve gastrectomy with loop bipartition is a new promising procedure that based on a new paradigm of helping GI facing and adapting to the modern diet without adding new morbidities with precise adsjusting of the neurohormonal aspects. Preliminary results points to potent simple safe procedure in treating obesity and metabolic syndrome.

Key words: Laparoscopic sleeve gastrectomy, loop bipartition, physiological technique

\section{INTRODUCTION:}

Overweight and obesity were estimated to cause 3.4 million deaths, $3.9 \%$ of years of life lost, and $3.8 \%$ of disability-adjusted life-years (DALYs) worldwide ${ }^{(\mathbf{1})}$.

Bariatric surgery is the most effective modality for long-term weight loss and for 
resolving the associated comorbidities. However, controversies exist regarding the ideal weight loss metabolic procedure. This allowed continuous search for new techniques $^{(2)}$.

The American College of Surgeons Bariatric Surgery Center Network has put laparoscopic sleeve gastrectomy (LSG) in the intermediate position between laparoscopic gastric banding and laparoscopic gastric bypass in term of reduction of BMI, complication rates and resolution of obesity related illness ${ }^{(3)}$.

Several randomized trials also demonstrated that LSG has a similar efficacy of weight reduction comparing to Roux-en-Y gastric bypass (RYGB) at short- to mid-term outcomes ${ }^{(4)}$.

Decrease of large parts of the ghrelinproducing stomach mass may account for its superiority to other gastric restrictive procedures in terms of weight loss and loss of sensation of hunger. Ghrelin is an orexigenic hormone whose plasmatic concentration regulates hunger and food intake ${ }^{(5)}$.

The acceptance of LSG is especially high in Asia because of the concern of remnant gastric cancer ${ }^{(6)}$.

LSG has now consisted more than $50 \%$ of the bariatric surgery in Asia and more than $70 \%$ in Japan where gastric cancer is the leading cancer death ${ }^{(7)}$.

However, the main long-term drawback of LSG is the development of gastroesophageal reflux disease (GERD) in around $15 \%$ of the patients ${ }^{(8)}$. $\mathrm{LSG}^{(\mathbf{9})}$.

This remains to be an important issue of

The culprit of developing DM and obesity are associated with the imbalance of foregut and hindgut alimentation (hyperalimentation of foregut and hypoalimentation of hindgut) due to over ingestion of high-calorie, highglycaemic index diet in modern society ${ }^{(\mathbf{1 0})}$.
All current metabolic procedures such as gastric bypass, duodenal switch (DS) and ileum interposition address and reverse this imbalance and their principles are based on the foregut or hindgut theory or the combination of both ${ }^{(11)}$.

Santoro et al. has recently reported his long-term data regarding sleeve gastrectomy with transit bipartition ( $\mathrm{SG}+\mathrm{TB})$, which is a similar operation to DS but without complete exclusion of duodenum in order to minimize nutritional complications ${ }^{(\mathbf{1 2})}$.

Mui et al. modified the operation by performing a loop rather than Roux-en-Y bipartition reconstruction in Santoro's operation $^{(11)}$.

Absence of prostheses or excluded segments, full endoscopic access, easy feasibility, completely reversible and associated with a metabolic corrective intervention in the context of adverse dietetic environments; all bring benefits to patients ${ }^{(\mathbf{1 3})}$.

There is a theoretical benefit by adding this step to sleeve gastrectomy to decrease the stomach tube pressure. This may potentially minimize the staple line leakage rate and development of GERD in $\mathrm{SG}^{(\mathbf{1 1 )}}$.

This anastomosis (gastroileal anastomosis) should be the most robust and safest as compared to other procedures with minimal tension. Moreover, gastrografin imaging showed that the preferential contrast passage through the anastomosis obviates the need for duodenal transection and without division of duodenum, it completely eliminates the possibility of duodenal stump leakage, which can be troublesome in single anastomosis duodenoileal bypass (SADI), duodenojejnal bypass (DJB) or duodenal switch (DS) ${ }^{(\mathbf{1 1})}$.

Sleeve gastrectomy with loop bipartition may be proven to be a very effective, safe and simple operation with numerous theoretical advantages over the current procedures for the treatment of obesity and diabetes ${ }^{(11)}$. 


\section{AIM OF THE WORK:}

The aim of this prospective study is to evaluate short-term outcomes and associated complications of laparoscopic sleeve gastrectomy with loop bipartition.

\section{PATIENTS AND METHODS:}

Our study was conducted on fifteen patients who met the National Institute of Health criteria for bariatric surgery. These patients were enrolled in a prospective study at Ain-Shams University Hospitals from December 2015 to May 2017) and they underwent laparoscopic sleeve gastrectomy with loop bipartition.A comprehensive assessment program was carefully structured so that a disciplined routine is followed in each patient. All patients were preoperatively evaluated with provision of extensive information.

The study included patietns aged 20-45 years with BMI $35-40 \mathrm{~kg} / \mathrm{m}^{2}$ accompanied by comorbidities or above $40 \mathrm{~kg} / \mathrm{m}^{2}$ and failure of nonoperative treatment for one year. While patients with previous bariatric or gastric surgery, BMI $>50 \mathrm{~kg} / \mathrm{m}^{2}$, active gastric ulcer disease, family history of upper GI malignancy or familial malignancies syndromes, non stabilized psychotic disorders, severe depression and personality disorders unless specifically advised by a psychiatrist experienced in obesity and alcohol abuse and/or drug dependencies were excluded from the study.

The documented preoperative, operative and postoperative follow up data for all patients were collected and reviewed and the outcome of surgery was evaluated.

Patients were subjected to preoperative assessment which includeda age and gender; full clinical assessment: full medical history and full clinical examination including BMI; full laboratory investigations:
Patient was described as diabetic if fasting blood sugar was $126 \mathrm{mg} / \mathrm{dl}$ or above or two hours postprandial blood sugar was $200 \mathrm{mg} / \mathrm{dl}$ or above or random blood sugar was $200 \mathrm{mg} / \mathrm{dl}$ or above, pulmonary function test, radiological imagin: Plain X-Ray chest and abdominal ultrasonography.

Each patient was routinely thoroughly evaluated by a multidisciplinary team (nutritionist, endocrinologist, psychologist, and surgeon) using a standardized protocol. All cases will be operated by consultant surgeon and according to the standardized technique described by Mui et al. ${ }^{(\mathbf{1 4})}$.

Surgeries were done by the same surgical team throughout the study. As part of their preparation, sleeve gastrecomy with loop bipartition was described to the candidates for surgery and the surgical procedure was reviewed with them in details with the possibility of conversion to open surgery and all the possible intraoperative, early and late postoperative complications.

Patients fulfilling the criteria of being surgery candidates signed a written consent for the operation as well as a consent for agreement to participate in this study. All the patients were subjected to sleeve gastrecomy with loop bipartition.

\section{Procedure:}

Preoperative medications: two grams of $3^{\text {rd }}$ generation cephalosporin antibiotic, $\mathrm{H}_{2}$ blocker, anti-emetic, deep vein thrombosis prophylaxis started $12 \mathrm{~h}$ before surgery with low molecular weight heparin subcutaneous injections.

\section{Operative technique:}

The patient was in French position. The first part of the operation is performed on the operating table under forced antiTrendelenburg position and the surgeon positioned between the legs of the patient.

The procedure started using Excel 12-mm optical trocar (Ethicon, USA) to enter the abdomen under direct vision about $20 \mathrm{~cm}$ 
below the xiphoid process and $3 \mathrm{~cm}$ to the left side of the midline. Pneumoperitoneum was achieved with carbon dioxide at $15 \mathrm{mmHg}$. Four additional ports were placed under direct vision, the same sites as in sleeve gastrectomy.

The technique commences with the devascularization of the greater curvature of the stomach with the harmonic scalpel (Ultracision, Ethicon Endo-Surgery, Inc., Johnson \& Johnson). The dissection then continued toward the gastroesophageal junction. The left cru was then completely freed of any attachments to avoid leaving a posterior pouch when constructing the sleeve in this region. Posterior attachments between the stomach and pancreas were then divided.

The stomach is then tabularized over a 36 French calibration tube, with a linear stapler (Echelon 60, Ethicon Endo-Surgery, Inc., Johnson \& Johnson) charged with a green cartridge, commencing $6 \mathrm{~cm}$ proximal to the pylorus.

Then, the table is changed to the horizontal position and the surgeon moves to the left-hand side of the patient to perform the second part of the operation. The ileocecal junction is identified and $250 \mathrm{~cm}$ is measured upwards. The selected loop is ascended a without division of the greater omentum, and a stapled isoperistaltic sideto-side to the anterior wall of the antrum of the stomach just $6 \mathrm{~cm}$ away from the pylorus with a linear stapler charged with a green cartridge, the diameter of ileal antrum anastomosis is not exceeding $3 \mathrm{~cm}$ in diameter to be not dependent.

The staple defect is closed with a single layer running $3 / 0$ absorbable suture. The transected stomach was then removed

\section{Preoperative data included:}

Age, gender, initial weight, initial body mass index (BMI), excess body weight, obesity comorbidities and treatment medications used (chest problems, diabetes, arterial hypertension and cardiac ischemia, hyperlipidemia, obstructive sleep apnea syndrome (OSAS), gallstones, urinary stress incontinence, joint pain, depression, infertility and heartburn).

\section{Operative data included:}

Operating time, intraoperative complications (bleeding, splenic injury, esophageal injury, liver tears and specimen retrieval problems) and stapler malfunction.

\section{Postoperative data included:}

Excess weight loss\%, BMI, hospital stay, early postoperative complications during the first month (e.g. fever, collection, bleeding, vomiting, leak and port site problems. complications more than 1 month after surgery as vomiting, reflux, stricture, intestinal obstruction, hypoalbuminemia, anemia were collected.

\section{Statistical analysis:}

Recorded data were analyzed using the statistical package for social sciences, version 20.0 (SPSS Inc., Chicago, Illinois, USA). Quantitative data were expressed as mean \pm standard deviation (SD). Qualitative data were expressed as frequency and percentage.

The following tests were done: Chisquare $\left(\chi^{2}\right)$ test of significance was used in order to compare proportions between qualitative parameters. Paired sample t-test of significance was used when comparing between related sample. The confidence interval was set to $95 \%$ and the margin of error accepted was set to $5 \%$. P-value $\leq 0.05$ was considered significant. 


\section{RESULTS:}

Table (1): Distribution of cases of laparoscopic sleeve gastrectomy with loop bipartition according to their demographic data regarding Gender, Age (Years), Weight $(\mathrm{Kg})$, Height $(\mathrm{Cm}), \mathrm{BMI}(\mathrm{Kg} / \mathrm{m} 2)$ and Excess weight $(\mathrm{Kg})(\mathrm{n}=15)$.

\begin{tabular}{|l|c|}
\hline Demographic data & Total $(\mathbf{n}=\mathbf{1 5})$ \\
\hline Gender & $10(66.7 \%)$ \\
\hline Female & $5(33.3 \%)$ \\
\hline Male & $24-42$ \\
\hline Age (Years) & {$[32.80 \pm 5.78]$} \\
\hline Range & $93-162$ \\
\hline Mean \pm SD & {$[124.80 \pm 20.10]$} \\
\hline Weight (Kg) & $155-182$ \\
\hline Range & {$[167.93 \pm 7.98]$} \\
\hline Mean \pm SD & $38-48.9$ \\
\hline Height $(\mathbf{C m})$ & {$[43.92 \pm 3.52]$} \\
\hline Range & $33-79$ \\
\hline Mean \pm SD & {$[54.20 \pm 13.89]$} \\
\hline BMI (Kg/m2)
\end{tabular}

As shown in table (1) ranged BMI 38-48.9, as well as excess weight 33-79 and mean $54.2 \pm 13.89$ of demographic data.

Table (2): Distribution of cases of laparoscopic sleeve gastrectomy with loop bipartition according to their co-morbidities regarding Fasting blood sugar (mg/dl), HTN, Obstructive sleep apnea, Hyperlipidemia, Reflux and Pain and Joint ( $\mathrm{n}=15)$.

\begin{tabular}{|c|c|}
\hline Comorbidities & Total $(\mathrm{n}=15)$ \\
\hline Hb A1c\% & $5.8-10$ \\
\hline Range & $8.23 \pm 1.41$ \\
\hline Mean \pm SD & $115-230$ \\
\hline Fasting blood sugar (mg/dl) & {$[171.93 \pm 38.22]$} \\
\hline Range & \\
\hline Mean \pm SD & $8(53.3 \%)$ \\
\hline No & $7(46.7 \%)$ \\
\hline Yes & $3(20 \%)$ \\
\hline DM & $12(80 \%)$ \\
\hline No & \\
\hline Yes & $12(80.0 \%)$ \\
\hline Obstructive sleep apnea & $3(20.0 \%)$ \\
\hline No & \\
\hline Yes & $9(60.0 \%)$ \\
\hline Hyperlipidemia & $6(40.0 \%)$ \\
\hline No & \\
\hline Yes & $13(86.7 \%)$ \\
\hline Reflux & $2(13.3 \%)$ \\
\hline No & $10(66.7 \%)$ \\
\hline Yes & $5(33.3 \%)$ \\
\hline Joint Pain & \\
\hline No & \\
\hline Yes & \\
\hline
\end{tabular}


As shown in table (2) that the ranged fasting blood sugar 115-230 with mean 171.93 \pm 38.22 , HTN 7 (46.7\%).

Table (3): Distribution of cases of laparoscopic sleeve gastrectomy with loop bipartition according to their operative data regarding operative time and intraoperative complications $(\mathrm{n}=15)$.

\begin{tabular}{|l|c|}
\hline Operative data & Total $(\mathrm{n}=15)$ \\
\hline Operative time / $\min$ & \\
\hline Range & $90-140$ \\
\hline Mean \pm SD & {$[108.00 \pm 16.67]$} \\
\hline Intraoperative complication & \\
\hline None & $13(86.7 \%)$ \\
\hline Bleeding & $1(6.7 \%)$ \\
\hline Bowel injury & $1(6.7 \%)$ \\
\hline
\end{tabular}

As shown in table (3) that the ranged operative time (min) 90-140 with mean $108.00 \pm 16.67$, while intraoperative complications bleeding $(6.7 \%)$ and bowel injury $(6.7 \%)$ of operative data.

Table (4): Comparison between pre-operative and after 12 months according to $\mathrm{HbA1C} \%$ ( $\mathrm{n}=15)$.

\begin{tabular}{|l|c|c|c|c|c|}
\hline Hb A1c\% & Pre operative & After 12 months & Mean Diff. & t-test & p-value \\
\hline Range & $5.8-10$ & $4.8-7$ & 2.51 & 6.291 & $<0.001^{* *}$ \\
\cline { 1 - 3 } Mean \pm SD & $8.23 \pm 1.41$ & $5.72 \pm 0.69$ & & & \\
\hline
\end{tabular}

This table shows highly statistically significant increase mean was pre-operative and after 12 months according to $\mathrm{HbA} 1 \mathrm{C} \%$.

Table (5): Distribution of cases of laparoscopic sleeve gastrectomy with loop bipartition according to their hospital stay (days) $(\mathrm{n}=15)$.

\begin{tabular}{|l|c|}
\hline Hospital stay (days) & Statistics \\
\hline Range & $1-5$ \\
\hline Mean \pm SD & {$[1.93 \pm 1.28]$} \\
\hline Median $(\mathrm{IQR})^{*}$ & $1(2)$ \\
\hline
\end{tabular}

As shown in table (5) that the ranged hospital stay ranged 1-5 with mean 1.93 and median 1 (2)

Table (6): The extent of the difference over the periods through EWL\% in the study group.

\begin{tabular}{|l|c|c|c|c|c|}
\hline EWL\% & Range & Mean \pm SD & Medan Diff. & t-test & p-value \\
\hline After 3 months & $25-50$ & $37.13 \pm 7.25$ & & & \\
\hline After 6 months & $45-83$ & $66.93 \pm 11.74$ & 29.9 & 9.332 & $<0.001^{* *}$ \\
\hline After 12 months & $80-100$ & $92.13 \pm 6.03$ & 55.0 & 14.391 & $<0.001^{* *}$ \\
\hline
\end{tabular}

This table shows highly statistically significant difference over the periods through EWL\% in the study group.

Table (7): Comparison between pre-operative and after 12 months according to HTN ( $n=15)$.

\begin{tabular}{|l|c|}
\hline HTN & Total $(\mathbf{n = 1 5})$ \\
\hline Pre-op HTN & $7(46.7 \%)$ \\
\hline Improved after 12 months & $2(13.3 \%)$ \\
\hline Resolved after 12 months & $5(33.3 \%)$ \\
\hline Chi-square test & $\mathbf{4 . 9 1 7}$ \\
\hline p-value & $\mathbf{0 . 0 2 7} *$ \\
\hline
\end{tabular}

This table shows statistically significant difference between pre-operative and after 12 months according to HTN. 
Table (8): Distribution of cases of laparoscopic sleeve gastrectomy with loop bipartition according to their postoperative complications "early \& late" regarding vomiting, marginal ulcer and nutitional hepatitis $(\mathrm{n}=15)$.

\begin{tabular}{|l|c|c|c|}
\hline Post-operative complication (early, late) & Total (n=15) & Chi-square test & p-value \\
\hline $\begin{array}{c}\text { Leakage } \\
\text { Yes } \\
\text { No }\end{array}$ & $\begin{array}{c}0(0 \%) \\
15(100 \%)\end{array}$ & ---- & ---- \\
\hline $\begin{array}{c}\text { Vomiting } \\
\text { Yes } \\
\text { No }\end{array}$ & $\begin{array}{c}2(13.3 \%) \\
13(86.7 \%)\end{array}$ & 0.532 & 0.465 \\
\hline $\begin{array}{c}\text { Marginal ulcer } \\
\text { Yes } \\
\text { No }\end{array}$ & $\begin{array}{c}1(6.7 \%) \\
14(93.3 \%)\end{array}$ & 0.035 & 0.852 \\
\hline $\begin{array}{c}\text { Hepatitis } \\
\text { Yes } \\
\text { No }\end{array}$ & $\begin{array}{c}1(6.7 \%) \\
14(93.3 \%)\end{array}$ & 0.035 & 0.852 \\
\hline
\end{tabular}

This table shows no statistically significant relation between leakage, vomiting, marginal ulcer and hepatitis according to cases of laparoscopic sleeve gastrectomy with loop bipartition.

Table (9): Distribution of cases of laparoscopic sleeve gastrectomy with loop bipartition according to their postoperative outcome Diabetes mellitus, HTN, Hyperlipidemia, Sleep apnea, Reflux and Joint pain $(\mathrm{n}=15)$.

\begin{tabular}{|c|c|c|c|}
\hline Postoperative outcomes & $\begin{array}{c}\text { Number } \\
\text { Of patients }\end{array}$ & Chi-square test & p-value \\
\hline $\begin{array}{c}\text { Diabetes mellitus } \\
\text { Yes } \\
\text { Resolved } \\
\text { improved }\end{array}$ & $\begin{array}{c}12(80.0 \%) \\
8(53.3 \%) \\
4(26.7 \%)\end{array}$ & 8.344 & $0.004 *$ \\
\hline $\begin{array}{l}\text { HTN } \\
\quad \text { Yes } \\
\quad \begin{array}{l}\text { Resolved } \\
\text { improved }\end{array}\end{array}$ & $\begin{array}{l}7(46.7 \%) \\
5(33.3 \%) \\
2(13.3 \%)\end{array}$ & 3.833 & $0.049 *$ \\
\hline $\begin{array}{c}\text { Hyperlipidemia } \\
\text { Yes } \\
\text { Resolved } \\
\end{array}$ & $\begin{array}{l}6(40.0 \%) \\
6(40.0 \%)\end{array}$ & 5.208 & $0.023 *$ \\
\hline $\begin{array}{l}\text { Sleep apnea } \\
\text { Yes } \\
\text { Resolved }\end{array}$ & $\begin{array}{l}3(20.0 \%) \\
3(20.0 \%)\end{array}$ & 1.481 & 0.224 \\
\hline $\begin{array}{l}\text { Reflux } \\
\quad \text { Yes } \\
\text { Resolved } \\
\end{array}$ & $\begin{array}{l}2(13.3 \%) \\
2(13.3 \%) \\
\end{array}$ & 0.532 & 0.467 \\
\hline $\begin{array}{l}\text { Joint pain } \\
\text { Yes } \\
\text { Resolved }\end{array}$ & $\begin{array}{l}5(33.3 \%) \\
5(33.3 \%)\end{array}$ & 3.833 & $0.049 *$ \\
\hline
\end{tabular}

This table shows statistically significant relation between diabetes mellitus and HTN to cases of laparoscopic sleeve gastrectomy with loop bipartition.

\section{DISCUSSION:}

Our study was conducted on fifteen patients. 10 females $(66.7 \%)$ and 5 male patients $(33.3 \%)$, the mean age was
$32.80 \pm 5.78$ (range, 24-42), the mean weight (Kg) was 124.80 \pm 20.10 (range, 93-162), the mean height $(\mathrm{cm})$ was $167.93 \pm 7.98$ (range, $155-182)$, the mean BMI $\left(\mathrm{Kg} / \mathrm{m}^{2}\right)$ was 43.92 \pm 3.52 (range, 38-48.9), the mean 
excess weight $(\mathrm{kg})$ was $54.20 \pm 13.89$ (range, 33-79).

Twelve patients were diabetics with mean fasting blood sugar level $(\mathrm{mg} / \mathrm{dl})$ 171.93 \pm 38.22 (range, 115-230) and mean $\mathrm{Hb} \mathrm{A}_{1} \mathrm{C} 8.23 \pm 1.41$ (range, 5.8-10). At 1 year post operative all patient $(100 \%)$ developed response with complete remission of diabetes in 8 patients $(66.6 \%)$ and improvement in 4 patients $(33.3 \%)$. There was significant decrease in $\mathrm{Hb} \quad \mathrm{A}_{1} \mathrm{C}$ to (5.72 $\pm 0.69 ; \mathrm{p}$ value $<0.001)$.

These results were comparable to other studies on these technique specially mahdy et al and salama et al, where mahdy et al reported complete remission in $(83.9 \%)$ and partial improvement in $(15.4 \%)$ of diabetic patients, salama et al reported improvement in all diabetic patients. ${ }^{(15)}$

Seven patients $(46.75 \%)$ were hypertensive, 5 patient $(71.4 \%)$ developed complete remission and 2 patient $(28.6 \%)$ showed improvement. There was significant difference between pre and post operative blood pressure with ( $p$ value $\mathbf{0 . 0 2 7}$ ). Our results were comparable to mahdy et al and emile et al as they recorded 83\%, 67\% improvement in all hypertensive patients respectively. ${ }^{(16)}$

Three patients (20\%) were diagnosed clinically to have obstructive sleep apnea, symptoms were varying from excessive daytime sleepiness, loud snoring, observed episodes of stopped breathing during sleep to abrupt awakenings accompanied by gasping and choking, all of them experienced symptoms resolution after 1 year follow up post operative.

Two patients $(13.3 \%)$ were complaining of GERD symptoms and they were receiving proton pump inhibitors medications. Upper GI endoscopy and gastrograffin studies were done to exclude hiatus hernia or eosophageal dysplasia. Post operative complete remission clinically and medication had stopped. Where as no patient complained of de novo
GERD postoperatively. This observation may be explained by the impact of adding an anastomosis between the distal gastric sleeve and the ileum which may reduce the intragastric pressure, thus contributing to the amelioration of the symptoms of GERD.

Six patients $(40.0 \%)$ had hyperlipidemia preoperative. At 12 months postoperative there were significant improvement in laboratory results, interestingly there were marked decrease in LDL, triglycerides level and increase in HDL levels.

Five patients (33.3\%) were complaining of joints pain mainly knee joint and some sort of disability in movements, all of them were clinically improved after exhibiting considerable weight loss post operative.

Regarding mean operative time (minutes) was 108.00 \pm 16.67 (range 90-140), it is very similar to results recorded by salama et al and emile et al but significantly more than those recorded by Kermansaravi et al. ${ }^{(16,17)}$

The mean hospital stay time (days) was $1.93 \pm 1.28$ (range 1-5) with 8 patients $(55.3 \%)$ discharged after one day. These is very comparable to salama et al and Kermansaravi et al. ${ }^{(\mathbf{1 7}, \mathbf{1 8})}$

we had reported intraoperative complications of two patients (13\%), one patient due to small bowel injury primary repair was done without any more consequences and the other patient had bleeding due to short gastric vessel injury that controlled successfully but he needed blood transfusion of one unit packed RBCS postoperative.

Postoperative four patients (26\%) developed complications, two complained of vomiting early postoperative that was controlled with antiemitics, One diagnosed after doing upper GI endoscope to have marginal ulcer 2 months postoperative and the patient improved after intense medical therapy. The last patient 4 months postoperative complained of abdominal discomfort, marked 
fatigue, weakness, nausea. The patient was investigated and there was mild liver enzymes elevation, hyoalbuminemia, hepatomegaly. He was diagnosed as NASH then he received medical and nutritional support and after follow up the condition markedly improved, he did not need any further intervention.

Complication incidence rate either intraoperative or postoperative were average in comparison to salama et al, mahdy et al, emile et al and kermansaravi et al. ${ }^{(\mathbf{1 6 - 1 8})}$

One of the reasons we attribute to the relative high incidence of complications is the small volume of the study sample versus other bariatric surgeries.

Regarding the main postoperative outcome we reported mean excess weight loss percentage (EWL\%) at 3,6,12 months respectively $\quad(37.13 \pm 7.25, \quad 66.93 \pm 11.74$, $92.13 \pm 6.03$ ).

Mahdy et al. reported $75 \%$ and $90 \%$ EWL six and 12 months after SASI bypass, respectively. A recent multi-centric study for mahdy et al also revealed an approximately $64 \%$ EWL 1 year after SASI. ${ }^{(19)}$

Another study emile et al resulted in EWL\% of 46.2 and 72.6 at 6 and 12 months after SASI bypass, respectively. ${ }^{(16)}$

Also, Madyan et al. showed 44.3 and 65.2 EWL\% in twenty super obese patients after 6 and 12 months, respectively. ${ }^{(20)}$

These results show that SASI is a highly effective procedure for weight loss, at least in the short term. Notably, all these studies had 12-month follow-ups, which could be due to the recent introduction of this investigational procedure.

The systematic review and metaanalysis done by Buchwald et al. included 621 studies for a total of 135,246 patients and compared bariatric surgical procedures for weight. This review indicates that BPD/DS is with a EWL of $73 \%$ at 2 years follow up, followed by RYGB (63\%), vertical banded gastroplasty (56\%), and
AGB (49\%). it seems that SG + loop bipartition is superior to other bariatric procedures regarding this aspect but we lacking of mid to long term follow up ${ }^{(21)}$.

In our study we found that most of the patients, after the procedure, do not have an altered frequency of stools evacuation or signals of malabsorption. They present an early sensation of satiety and in some cases, especially with fatty meals, some degree of food averseness. All of them refer an evident change in their relation to food, especially in taste, which we attribute to enterohormonal changes ${ }^{(19)}$.

As we know that distal gut hormones are satietogenic and they reduce gastric emptying, SG + loop bipartition significantly reduces meal size and overeating and leads to changing taste preferences ${ }^{(\mathbf{1 5})}$.

Sleeve gastrectomy is considered high pressure tube. But gastroileal anastomosis is a gastric drainage, so this condition improved, we noted that no postoperative leakage incidence were reported concerning bipartition $^{(20)}$.

In our study we recorded that Sleeve gastrectomy with loop bipartition has strong impact on resolution of comorbidities in comparison with BPD, DS, RYGB ${ }^{(22)}$.

Regarding techniqual aspects loop bipartition is potentially safe and feasible to be reversible in case of excessive weight loss or unresponsive malnutrition. It also permissive to convert it to other bariatric procedures but these do not reported yet.

\section{Conclusion:}

In conclusion, Sleeve gastrectomy with loop bipartition is a new promising procedure that based on a new paradigm of helping GI facing and adapting to the modern diet without adding new morbidities with precise adsjusting of the neurohormonal aspects. Preliminary results points to potent simple safe procedure in treating obesity and metabolic syndrome. More studies are needed for assessing long term 
results and knowing more about the biochemical chnges of bipartition. According to our study it could be the ideal metabolic procedure in the future.

\section{REFERENCES:}

1. Marie N, Tom F and et al (2014): the lancet journal; Global, regional, and national prevalence of overweight and obesity in children and adults during 1980-2013: a systematic analysis for the Global Burden of Disease Study 2013; Volume 384, 45: 766-781.

2. Abdelbaki T, Huang $\mathrm{C}$ and et al (2012): Obes Surg; Gastric Plication for Morbid Obesity: a Systematic Review; 22:16331639.

3. Hutter M, Schirmer B and et al (2011): Ann Surg; First report from the American College of Surgeons Bariatric Surgery Center Network: laparoscopic sleeve gastrectomy has morbidity and effectiveness positioned between the band and the bypass; 254(3); discussion 420422:410-420.

4. Peterli R, Borbely Y and et al (2013): Ann Surg; Early results of the Swiss multicentre bypass or sleeve study (SM-BOSS): A prospective randomized trial comparing laparoscopic sleeve gastrectomy and Rouxen-Y gastric bypass; 258(5):690-695.

5. Langer F, Reza Hoda M and et al (2005): Obes Surg; Sleeve gastrectomy and gastric banding: Effects on plasma ghrelin levels; 15:1024-29.

6. Wu C, Lee $\mathrm{W}$ and et al (2013): Asian J Endosc Surg; Gastric cancer after minigastric bypass surgery: A case report and literature review; 6(4):303-306.

7. Sasaki A, Wakabayashi $G$ and Yonei $Y$ (2014): J Gastroenterol; Current status of bariatric surgery in Japan and effectiveness in obesity and diabetes; 49(1):57-63.

8. Himpens J, Dobbeleir $\mathrm{J}$ and Peeters $\mathrm{G}$ (2010): Ann Surg; Long-term results of laparoscopic sleeve gastrectomy for obesity; 252(2):319-324.
9. Santonicola A, Angrisani L and et al (2014): Surg Obes Relat Dis; The effect of laparoscopic sleeve gastrectomy with or without hiatal hernia repair on gastroesophageal reflux disease in obese patients; 10(2):250-256.

10. Santoro S, Malzoni C and et al (2006): Obes Surg; Digestive adaptation with intestinal reserve: a neuroendocrine-based operation for morbid obesity; 16:13711379.

11. Mui W, Lee D and Lam K (2014): Int J Surg Case Rep; Laparoscopic sleeve gastrectomy with loop bipartition: a novel metabolic operation in treating obese type II diabetes mellitus; 5(2):56-58.

12. Santoro S, Castro L and et al (2012): Ann Surg; Sleeve gastrectomy with transit bipartition: a potent intervention for metabolic syndrome and obesity; 256:104110.

13. Lucchese M and Scopinaro N (2015): Springer Internatio4nal Publishing Switzerland; Minimally Invasive Bariatric and Metabolic Surgery: Principles and Technical Aspects; 465(13):133-45.

14. Mui W, Lee D and Lam K (2014): International journal of surgery case reports; Laparoscopic sleeve gastrectomy with loop bipartition: A novel metabolic operation in treating obese type II diabetes mellitus.. $\quad 5.56-58$. 10.1016/j.ijscr.2013.12.002.

15. Mahdy T, Emile S and et al (2019): Obesity Surgery; Evaluation of the Efficacy of Single Anastomosis Sleeve Ileal (SASI) Bypass for Patients with Morbid Obesity: a Multicenter Study; 30. 10.1007/s11695-019-04296-3.

16. Emile S, Madyan A and et al (2020): Surgical Endoscopy; Single anastomosis sleeve ileal (SASI) bypass versus sleeve gastrectomy: a case-matched multicenter study; 3. 10.1007/s00464-020-07430-w.

17. Kermansaravi M, Kabir A and Pazouki A (2020): Obesity Surgery; 1-Year Follow-up of Single Anastomosis Sleeve Ileal (SASI) Bypass in Morbid Obese Patients: Efficacy and Concerns; 10.1007/s11695-020-047810 . 
18. Salama T, Sabry K \& Ghamrini Y (2016): Journal of Investigative Surgery; Single Anastomosis Sleeve Ileal Bypass: New Step in the Evolution of Bariatric Surgeries; 30. 1-6. 10.1080/08941939.2016.1241841.

19. Mahdy T, Wahedi A and Schou C (2016): International journal of surgery (London, England); Efficacy of single anastomosis sleeve ileal (SASI) bypass for type-2 diabetic morbid obese patients: gastric bipartition, a novel metabolic surgery procedure: A Retrospective Cohort Study. 34. 10.1016/j.ijsu.2016.08.018.
20. Madyan A, Emile SH and et al (2020): Surg Laparosc Endosc Percutan Tech; Laparoscopic single anastomosis sleeve ileal (SASI) bypass for patients with morbid obesity: technical description and short-term outcomes; 30(2):e13-e7.

21. Buchwald H, Estok R and et al (2009): Am $\mathrm{J}$ Med; Weight and type 2 diabetes after bariatric surgery: systematic review and meta-analysis; 122(3): 248-56.e5.

22. Scopinaro N (2015): springer int.; Laparoscopic Biliopancreatic Diversion; 10.1007/978-3-319-15356-8_20. 


\title{
Mohamed K. Mansey, et al.,
}

\author{
دراسة لتقييم جراحة تكميم المعدة بالمنظار الجراحى مع تحويل مسار جزئى لعلاج السمنة المرضية

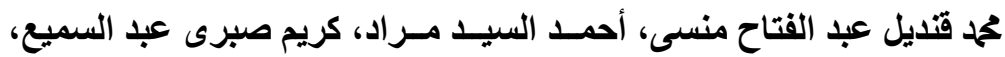 \\ حسام جمال الاين رضوان مسران، كريم \\ قسم الجر احة العامة

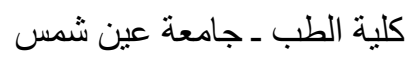

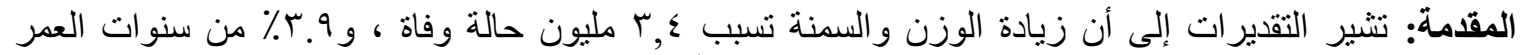

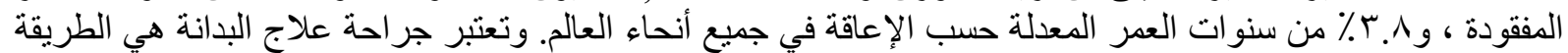

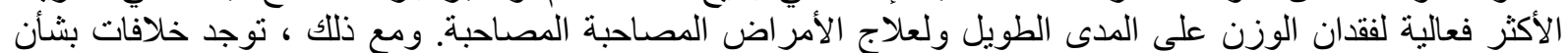
إجر اء التمثيل الغذائي المثنالي لفقدان الوزن الفئ سمح هذا بالبحث المستمر عن تقنيات جديدة.

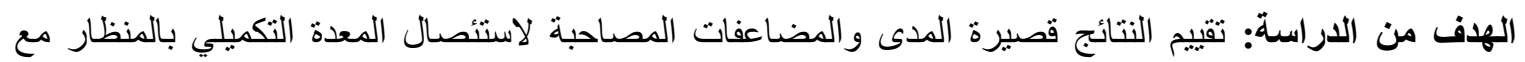
تحويل مسار جزئى لعلاج السمنة المرضية.

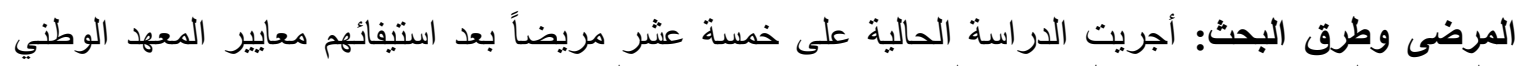

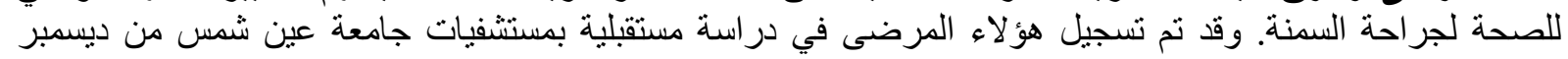

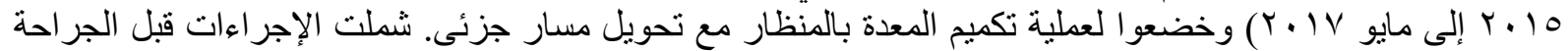

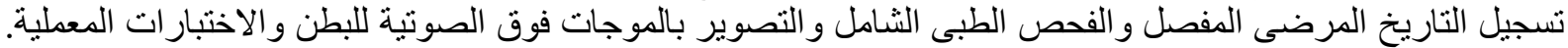
وتم تنفيذ العمليات بالمنظار الجر احى.

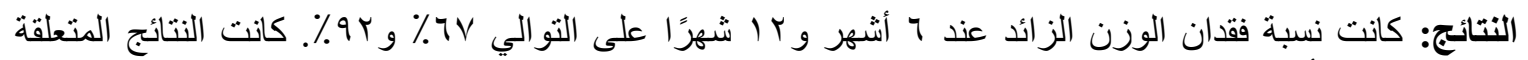

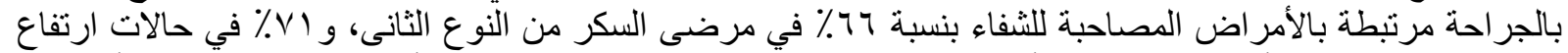

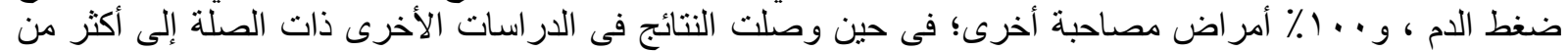

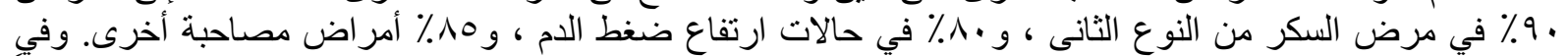

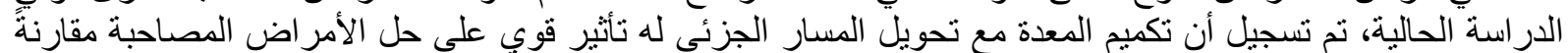

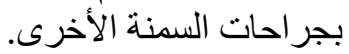

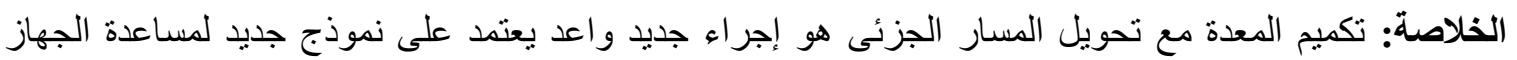

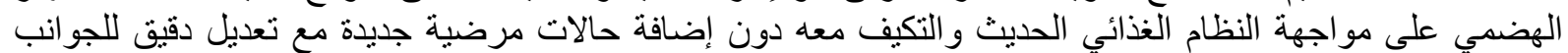

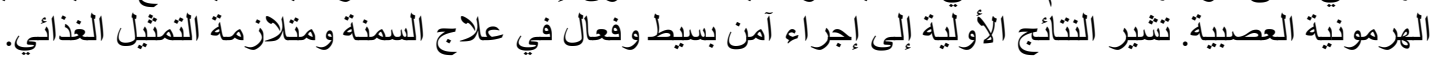

